nephron

Practice

\title{
UK Renal Registry 18th Annual Report: Chapter 4 Demography of Patients Receiving Renal Replacement Therapy in Paediatric Centres in the UK in 2014
}

\author{
Alexander J Hamilton ${ }^{a}$, Fiona Braddon ${ }^{a}$, Anna Casula ${ }^{a}$, Carol Inward ${ }^{b}$, Malcolm Lewis ${ }^{c}$, \\ Tamara Mallett $^{\mathrm{b}}$, Heather Maxwell ${ }^{\mathrm{d}}$, Catherine $\mathrm{O}^{\prime}$ Brien $^{\mathrm{e}}$, Yincent Tse ${ }^{\mathrm{f}}$, Manish D Sinha ${ }^{\mathrm{g}}$

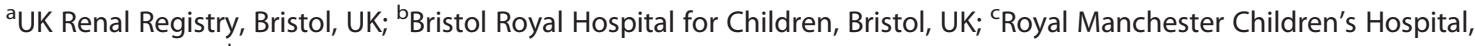 \\ Manchester, UK; ${ }^{d}$ Royal Hospital for Children, Glasgow, UK; ${ }^{~}$ Birmingham Children's Hospital, Birmingham, UK; \\ ${ }^{f} G r e a t$ North Children's Hospital, Newcastle Upon Tyne, UK; ${ }^{9}$ Evelina London Children's Hospital, London, UK
}

\section{Key words}

Adolescents · Aetiology · Children • Demography . Established renal failure - Incidence - Prevalence - Preemptive transplantation . Renal replacement therapy . Survival · Young adults

\section{Summary}

- A total of 917 children and young people under 18 years with established renal failure (ERF) were receiving treatment at paediatric nephrology centres in 2014.

- At the census date (31st December 2014), 79.3\% of prevalent paediatric patients aged $<18$ years had a functioning kidney transplant, $11.2 \%$ were receiving haemodialysis (HD) and 9.5\% were receiving peritoneal dialysis (PD).

- In patients aged $<16$ years, prevalence of ERF was 60.4 per million age related population (pmarp) and the incidence 9.4 pmarp.
- The most common primary renal diagnosis was renal dysplasia \pm reflux, present in $32.6 \%$ of prevalent paediatric patients aged $<16$ years.

- About a third of patients had one or more reported comorbidity at onset of renal replacement therapy (RRT).

- The improvement in rates of pre-emptive transplantation for those referred early has been maintained over the last 10 years at $37.5 \%$, compared to $27.4 \%$ in 2000-2004.

- At transfer to adult services, $90.3 \%$ of patients had a functioning kidney transplant.

- Survival during childhood amongst children commencing RRT was the lowest in those aged less than two years compared to those aged 12 to less than 16 years with a hazard ratio of 4.1 (confidence interval 2.2-8.0), and in those receiving dialysis compared to having a functioning transplant with a hazard ratio of 6.3 (confidence interval 3.9-10.2).

\section{KARGER}

Fax +4161306 1234 E-Mail karger@karger.com www.karger.com/nef $1660-8151 / 16 / 1325-099 \$ 39.50 / 0$

Karger open access

This article is licensed under the Creative Commons AttributionNonCommercial-NoDerivatives 4.0 International License (CC BYNC-ND) (http://www.karger.com/Services/OpenAccessLicense). Usage and distribution for commercial purposes as well as any distribution of modified material requires written permission.
Manish D Sinha

UK Renal Registry, Southmead Hospital, Southmead Road, Bristol, BS10 5NB, UK

Email: renalregistry@renalregistry.nhs.uk 


\section{Introduction}

The UK Renal Registry (UKRR) publishes an annual report detailing demographics, clinical, haematological and biochemical parameters for patients managed in UK paediatric nephrology centres. In the UK, care for children, adolescents and young adults with established renal failure (ERF) requiring renal replacement therapy (RRT) is a tertiary service provided in 13 paediatric nephrology centres. All centres are equipped to provide peritoneal dialysis (PD) and haemodialysis (HD), with 10 centres also undertaking kidney transplantation.

Young adults aged 16-18 may be managed in either paediatric or adult services, depending on local practices, educational and social factors. In this report, data for all patients aged under 18 years in UK paediatric nephrology centres reported to the UKRR with a particular focus on the demographics of those aged 16 and under are described.

In the UK in 2013, the prevalence rate of treated ERF in children aged under 16 years was 58.2 and the incidence rate was 9.3 per million age related population (pmarp) [1].

The objectives of this report are:

(i) To describe the UK prevalence, incidence, causes of ERF and modality of treatment of children, adolescents and young adults on RRT on 31st December 2014

(ii) To describe trends in (i) over the past 15 years, and

(iii) To describe pre-emptive transplantation rates and survival of children, adolescents and young adults on RRT aged $<16$ years old in the UK.

All 13 paediatric nephrology centres in the UK contributed data to the UKRR, mandated in England by the NHS service specification which requires 'paediatric renal units to submit data comprising the national renal data set to the UK Renal Registry on all patients on renal replacement therapy' [2]. In most cases this is via an annual extract of a centre's clinical computer system which is checked, validated and loaded onto the UKRR paediatric database. Where this is not possible, data returns are completed using a data collection form and manually loaded. At each return, missing data items are sought. Centres pay a capitation fee in order to support the process. Currently, the UKRR paediatric and adult databases are maintained separately and a future merger is planned.

\section{Methods}

Centres arranged for their own data to be extracted and sent to the UKRR for processing by clinical informaticians. For this report, end of year numbers were required by the 31st January 2015 and the full data by the 31st March 2015, however, the last submission was received on the 3rd August 2015. Overall responsibility for the process is held by the Chair of the British Association for Paediatric Nephrology (BAPN) Audit \& Registry Committee.

The content and analyses contained in the paediatric chapters are discussed and agreed by the BAPN Audit \& Registry Committee members.

In this report, patient groups are described as:

(i) 'prevalent' group: patients who were receiving RRT on the 31st December 2014

(ii) 'incident' group: patients who started RRT between 1st January and 31st December 2014

(iii) '5 year' groups: patients who started RRT in the periods of 2000-2004, 2005-2009 and 2010-2014.

The populations used to calculate the incidence and prevalence were obtained from the Office for National Statistics (ONS) [3]. The mid-2014 population estimate produced by the ONS, based on the 2011 Census, was used to calculate the 2014 incidence and prevalence; the 2002 Census data used for the 2000-2004 group, the 2007 data for the 2005-2009 group and the 2012 data for the 2010-2014 group. Incidence and prevalence for 1618 year olds are not reported. This is because data would not be representative of the UK as a whole as they may also be managed in adult services.

Statistical analyses were performed using SAS 9.3, with group analyses using the Chi-square test and median analyses using the Kruskal-Wallis test. Infants under the age of three months and 'late presenters' (defined as those commencing dialysis within three months following first review by a paediatric nephrologist) were excluded from analyses when calculating pre-emptive transplantation rates. For survival analysis, only patients starting RRT between 1st January 2000 and 31st December 2013 were included to ensure a minimum of one year follow up at the census date, and were followed up to a maximum age of 16 years. As the maximum age of follow up was restricted to 16 years it was not possible to calculate 10 year survival probabilities for patients starting RRT aged $>8$ years, or 5 year survival probability for children starting RRT aged $>12$ years. A Cox regression model was used in calculating hazard ratios for patient survival, adjusting for gender, age at start of RRT, and RRT modality as a time dependent variable. Survival probabilities were calculated using univariate Kaplan Meier curves.

\section{Results}

\section{Data returns}

Centres used a variety of clinical data systems to facilitate returns. In 2014, the majority of paediatric 
Table 4.1. Data completeness for the paediatric prevalent ERF population in 2014

\begin{tabular}{|c|c|c|c|c|c|c|}
\hline Centre & $N$ & $\begin{array}{l}\text { First seen } \\
\text { date }\end{array}$ & $\begin{array}{l}\text { Height at } \\
\text { RRT start }\end{array}$ & $\begin{array}{l}\text { Weight at } \\
\text { RRT start }\end{array}$ & $\begin{array}{l}\text { Creatinine at } \\
\text { RRT start }\end{array}$ & $\begin{array}{c}\text { Primary renal } \\
\text { diagnosis }\end{array}$ \\
\hline Blfst_P* & 30 & 90.0 & 76.7 & 83.3 & 90.0 & 96.7 \\
\hline Bham_P* & 103 & 98.1 & 93.2 & 97.1 & 97.1 & 100.0 \\
\hline Brstl_ ${ }^{*}$ & 57 & 94.7 & 89.5 & 94.7 & 96.5 & 100.0 \\
\hline L Eve_P* & 99 & 98.0 & 69.7 & 75.8 & 77.8 & 100.0 \\
\hline L GOSH_P* & 185 & 96.8 & 87.0 & 94.1 & 95.1 & 93.0 \\
\hline Leeds_P* & 86 & 100.0 & 90.7 & 100.0 & 100.0 & 100.0 \\
\hline Livpl_P & 41 & 87.8 & 70.7 & 75.6 & 85.4 & 87.8 \\
\hline Manch_P* & 85 & 95.3 & 89.4 & 96.5 & 96.5 & 100.0 \\
\hline Newc_P* & 37 & 100.0 & 100.0 & 100.0 & 100.0 & 100.0 \\
\hline
\end{tabular}

${ }^{*}$ Denotes centres undertaking paediatric kidney transplantation

renal centres were using Vitaldata (Birmingham, Cardiff, Glasgow, Leeds, London Great Ormond Street) with others using Proton (Bristol, Nottingham), Clinicalvision (Manchester, Newcastle), Mediqal (Belfast), CyberREN (Liverpool) or bespoke systems (London Evelina, Southampton).

In 2014, most centres submitted data electronically $(n=12)$ to the UKRR via extracts. The remaining centre used paper forms which were manually entered into the database.

Overall data completeness was excellent for the following: age and gender (100\%), ethnicity (98.0\%), start and 90 day treatment modality $(99.7 \%)$ and start date (99.5\%). Completeness of other data items ranged from $84.1 \%$ to $97.8 \%$ and is shown by centre in table 4.1 . Centre size and type (if undertaking paediatric kidney transplantation) is also displayed.
The UK paediatric prevalent ERF population in 2014

A total of 917 children and young people under 18 years with ERF were receiving treatment at paediatric nephrology centres in 2014 (table 4.1). Of these, 734 were under 16 years of age. Table 4.2 shows the number of patients receiving RRT and rate of RRT by age group and gender. There were more than ten times the number of teenagers than infants receiving RRT. The prevalence of RRT increased with age and was higher in males across all age groups with an overall male to female ratio of $1.7: 1$. The reported prevalence in under 16 year olds was 60.4 pmarp.

Table 4.3 shows the prevalence of childhood ERF by ethnicity. Children from ethnic minorities displayed higher RRT prevalence rates when compared with White children, with South Asian children displaying the highest rates.

Table 4.2. The UK paediatric prevalent ERF population $<16$ years old in 2014 , by age group

\begin{tabular}{|c|c|c|c|c|c|c|c|}
\hline \multirow[b]{2}{*}{ Age group (years) } & \multicolumn{2}{|c|}{ All patients } & \multicolumn{2}{|c|}{ Males } & \multicolumn{2}{|c|}{ Female } & \multirow{2}{*}{$\begin{array}{c}\mathrm{M}: \mathrm{F} \text { rate } \\
\text { ratio }\end{array}$} \\
\hline & $N$ & pmarp & $N$ & pmarp & $N$ & pmarp & \\
\hline $2-<4$ & 49 & 29.8 & 35 & 41.5 & 14 & 17.4 & 2.4 \\
\hline $4-<8$ & 163 & 51.3 & 107 & 65.9 & 56 & 36.1 & 1.8 \\
\hline $8-<12$ & 214 & 73.8 & 140 & 94.4 & 74 & 52.3 & 1.8 \\
\hline
\end{tabular}

pmarp - per million age related population 
Table 4.3. The UK paediatric prevalent ERF population $<16$ years old by age and ethnic group ${ }^{\mathrm{a}}$ in 2014

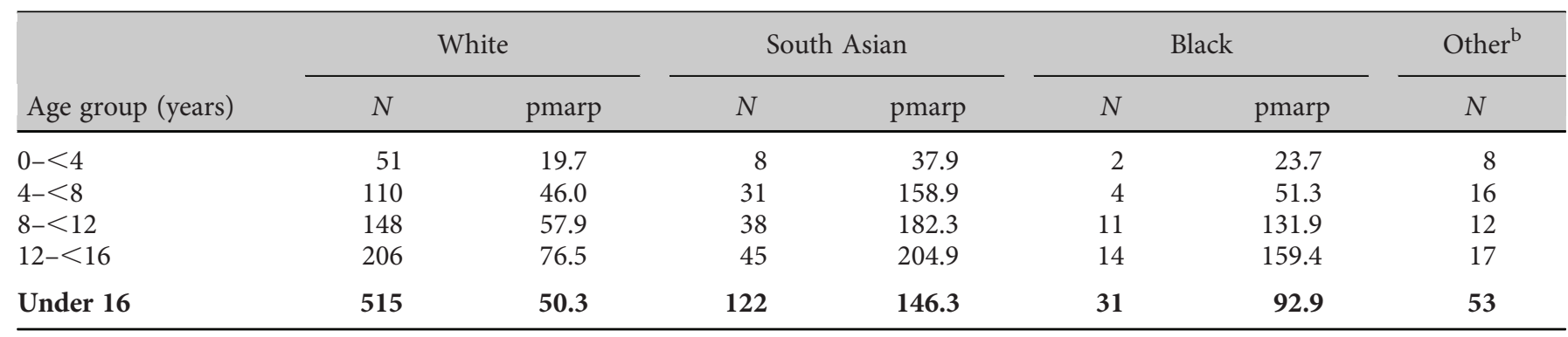

pmarp - per million age related population

a ethnicity data missing for 13 children, not included in this table

bmarp not expressed for group 'Other', as heterogeneous group

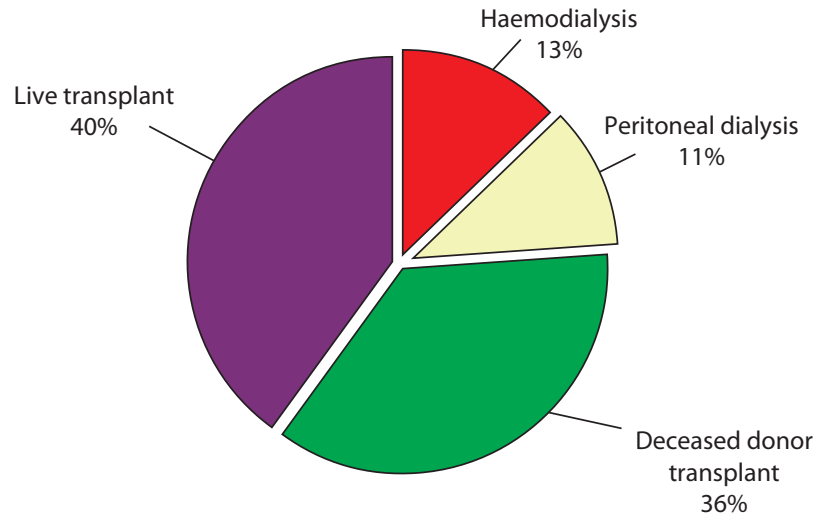

Fig. 4.1. RRT treatment used by prevalent paediatric patients $<16$ years old in 2014

\section{Modality of treatment}

The majority of prevalent paediatric patients under 16 years old in 2014 had a functioning transplant, as shown in figure 4.1. The ratio of living to deceased donor transplants was $1: 1$.

Almost half of patients started RRT on PD, similar

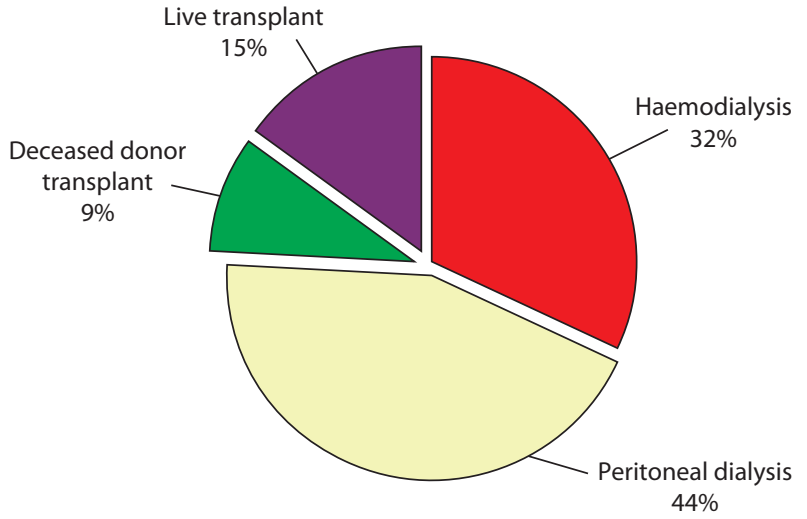

Fig. 4.2. Treatment modality at start of RRT in prevalent paediatric patients $<16$ years old in 2014

proportions started with a pre-emptive transplant or on $\mathrm{HD}$, as displayed in figure 4.2.

Analysis by age shows the proportion of those receiving dialysis as current treatment is lower in older children with increasing use of transplantation (particularly from deceased donors) in older patients, as seen in table 4.4.

Table 4.4. Current treatment modality by age in the prevalent paediatric ERF population in 2014

\begin{tabular}{|c|c|c|c|c|c|c|c|c|c|}
\hline \multirow{3}{*}{$\begin{array}{l}\text { Age group } \\
\text { (years) }\end{array}$} & \multirow[b]{3}{*}{ Total } & \multicolumn{8}{|c|}{ Current treatment } \\
\hline & & \multicolumn{2}{|c|}{$\mathrm{HD}$} & \multicolumn{2}{|c|}{$\mathrm{PD}$} & \multicolumn{2}{|c|}{ Live transplant } & \multicolumn{2}{|c|}{ Deceased donor transplant } \\
\hline & & $N$ & $\%$ & $N$ & $\%$ & $N$ & $\%$ & $N$ & $\%$ \\
\hline $0-<2$ & 23 & 8 & 34.8 & 13 & 56.5 & 2 & 8.7 & 0 & 0.0 \\
\hline $2-<4$ & 49 & 19 & 38.8 & 13 & 26.5 & 13 & 26.5 & 4 & 8.2 \\
\hline $4-<8$ & 163 & 21 & 12.9 & 16 & 9.8 & 90 & 55.2 & 36 & 22.1 \\
\hline $8-<12$ & 214 & 22 & 10.3 & 15 & 7.0 & 93 & 43.5 & 84 & 39.3 \\
\hline $12-<16$ & 285 & 23 & 8.1 & 25 & 8.8 & 99 & 34.7 & 138 & 48.4 \\
\hline $16-<18$ & 183 & 10 & 5.5 & 5 & 2.7 & 76 & 41.5 & 92 & 50.3 \\
\hline Under 16 & 734 & 93 & 12.7 & 82 & 11.2 & 297 & 40.5 & 262 & 35.7 \\
\hline Under 18 & 917 & 103 & 11.2 & 87 & 9.5 & 373 & 40.7 & 354 & 38.6 \\
\hline
\end{tabular}

HD - haemodialysis; PD - peritoneal dialysis 
Table 4.5. Number, percentage and gender by primary renal disease in the prevalent paediatric ERF population under 16 years in 2014

\begin{tabular}{|c|c|c|c|c|c|}
\hline Renal dysplasia \pm reflux & 239 & 32.6 & 153 & 86 & 1.8 \\
\hline Obstructive uropathy & 135 & 18.4 & 131 & 4 & 32.8 \\
\hline Congenital nephrotic syndrome & 69 & 9.4 & 37 & 32 & 1.2 \\
\hline Tubulo-interstitial disease & 51 & 6.9 & 22 & 29 & 0.8 \\
\hline Uncertain aetiology & 38 & 5.2 & 20 & 18 & 1.1 \\
\hline Metabolic & 29 & 4.0 & 17 & 12 & 1.4 \\
\hline Malignancy \& associated disease & 16 & 2.2 & 4 & 12 & 0.3 \\
\hline Missing & 15 & 2.0 & 10 & 5 & 2.0 \\
\hline Total & 734 & & 466 & 268 & 1.7 \\
\hline
\end{tabular}

Treatment in the youngest age groups is subject to variation as there were few patients. There was no difference in modality by gender. There was significantly higher transplantation in Whites versus non-Whites $(p=0.001)$.

\section{Cause of ERF}

Renal dysplasia with or without reflux nephropathy was the commonest primary renal diagnosis (PRD) in prevalent patients under 16 years in 2014, shown in table 4.5. The high male to female ratio in those with obstructive uropathy was a result of posterior urethral valves. Figure 4.3 displays the percentage of patients in each diagnostic category for incident and prevalent cohorts, and shows a disproportionately high amount of uncertain diagnoses in incident compared to prevalent

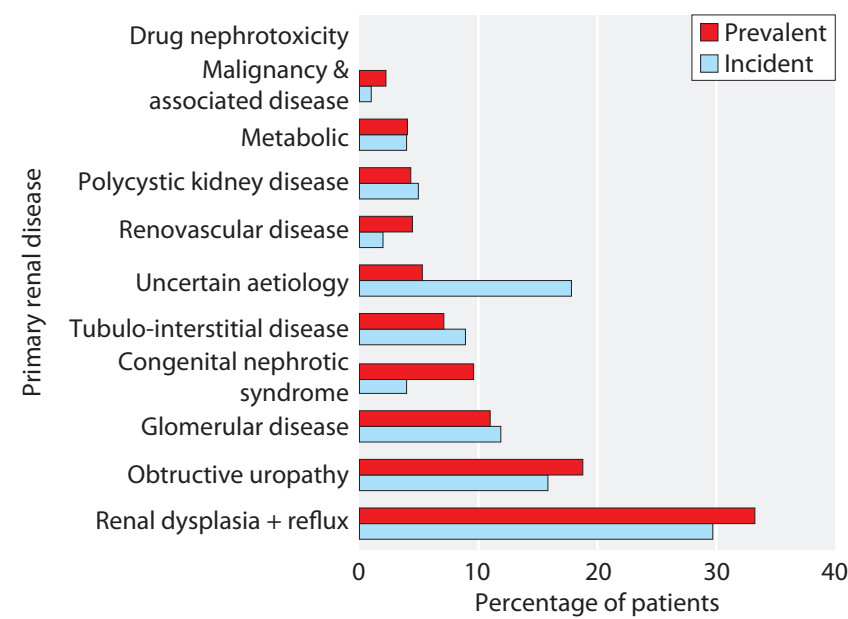

Fig. 4.3. Primary renal disease percentage in incident and prevalent paediatric patients in 2014 for whom a causative diagnosis was reported patients, although the absolute numbers are small here. Missing PRD data has increased from $0.4 \%$ in 2011 [4] to $2.0 \%$ in 2014 , some of which may be due to a PRD not being assigned until the results of genetic tests have been received.

The commonest comorbidities at the onset of RRT in 2014 were congenital abnormalities, developmental delay and syndromic diagnoses, reported in $7.5 \%$ of patients respectively, shown in table 4.6. Although the majority of children are reported to have no comorbidities, there was considerable variation between centres (e.g. no

Table 4.6. Frequency of registered comorbidities at onset of RRT in prevalent paediatric patients aged $<16$ years with ERF in 2014

\begin{tabular}{lrc}
\hline Comorbidity & $N$ & $\begin{array}{c}\text { Percentage of all } \\
\text { RRT patients }\end{array}$ \\
\hline Congenital abnormality & 55 & 7.5 \\
Developmental delay & 55 & 7.5 \\
Syndromic diagnosis & 55 & 7.5 \\
Prematurity & 42 & 5.7 \\
Consanguinity & 30 & 4.1 \\
Chromosomal abnormality & 12 & 1.6 \\
Liver disease & 12 & 1.6 \\
Congenital heart disease & 9 & 1.2 \\
Family member with ERF & 9 & 1.2 \\
Cerebral palsy & 8 & 1.1 \\
Malignancy & 6 & 0.8 \\
Neural tube defect & 4 & 0.5 \\
Psychological disorder & 4 & 0.5 \\
Diabetes & 1 & 0.1 \\
No reported comorbidity & $\mathbf{5 2 8}$ & $\mathbf{7 1 . 9}$ \\
One reported comorbidity & $\mathbf{1 3 6}$ & $\mathbf{1 8 . 5}$ \\
Two or more comorbidities & $\mathbf{7 0}$ & $\mathbf{9 . 5}$ \\
\hline
\end{tabular}

RRT - renal replacement therapy; ERF - established renal failure 
Table 4.7. The incident paediatric ERF population $<16$ years old in the UK in 2014, by age group and gender

\begin{tabular}{|c|c|c|c|c|c|c|c|}
\hline \multirow[b]{2}{*}{ Age group (years) } & \multicolumn{2}{|c|}{ All patients } & \multicolumn{2}{|c|}{ Males } & \multicolumn{2}{|c|}{ Females } & \multirow[b]{2}{*}{$\mathrm{M}: \mathrm{F}$ ratio } \\
\hline & $N$ & pmarp & $N$ & pmarp & $N$ & pmarp & \\
\hline $0-<2$ & 14 & 8.9 & 10 & 12.4 & 4 & 5.2 & 2.4 \\
\hline $2-<4$ & 17 & 10.3 & 10 & 11.9 & 7 & 8.7 & 1.4 \\
\hline $4-<8$ & 25 & 7.9 & 18 & 11.1 & 7 & 4.5 & 2.5 \\
\hline $8-<12$ & 25 & 8.6 & 21 & 14.2 & 4 & 2.8 & 5.0 \\
\hline $12-<16$ & 33 & 11.6 & 18 & 12.3 & 15 & 10.8 & 1.1 \\
\hline Under 16 & 114 & 9.4 & 77 & 12.4 & 37 & 6.2 & 2.1 \\
\hline
\end{tabular}

pmarp - per million age related population

comorbidity reported in $92 \%$ of patients from Cardiff, and $40 \%$ of patients from Manchester). This may be due to small numbers in some centres or reporting practice and is subject to a current data quality exercise in order to evaluate whether there are genuine differences between centres in willingness to accept patients with comorbidity onto the RRT programme.

\section{The UK incident paediatric ERF population in 2014}

There were 120 patients under 18 years of age who commenced RRT at paediatric renal centres in 2014. As previously, the following analyses are restricted to the 114 patients who were under 16 years of age.

The incidence of RRT was 9.4 pmarp in 2014. Patients commencing RRT in 2014 are displayed by age and gender in table 4.7, although any apparent differences may be a result of small group sizes.

Table 4.8 shows that the reported incidence of RRT has remained steady since 2000, with the highest incidence seen in both the youngest and oldest age groups.

\section{Trends in ERF demographics}

There were 1,697 children and adolescents under 16 years of age who had received RRT in the UK over the
Table 4.8. Reported average incidence by age group in 5 -year time periods of children under 16 years of age commencing RRT

\begin{tabular}{lccc}
\hline \multirow{2}{*}{$\begin{array}{l}\text { Age group } \\
\text { (years) }\end{array}$} & \multicolumn{3}{c}{ Per million age related population } \\
\cline { 2 - 4 } & $2000-2004$ & $2005-2009$ & $2010-2014$ \\
\hline $0-<2$ & 10.9 & 14.6 & 11.8 \\
$2-<4$ & 6.4 & 6.7 & 9.0 \\
$4-<8$ & 5.5 & 7.5 & 6.1 \\
$8-<12$ & 8.8 & 8.8 & 9.0 \\
$12-<16$ & 12.7 & 14.8 & 11.7 \\
Under $\mathbf{1 6}$ & $\mathbf{9 . 0}$ & $\mathbf{1 0 . 6}$ & $\mathbf{9 . 3}$ \\
\hline
\end{tabular}

15 year period between 2000 and 2014. Table 4.9 demonstrates slight fluctuations over time in the ages of patients starting RRT. Table 4.10 shows overall ethnicity proportions are similar, with slightly more in the 'Other' ethnic group and slightly fewer in the White group more recently. Table 4.11 demonstrates that the overall proportions between paediatric renal centres have remained largely unchanged since 2000-2004.

Table 4.12 shows the number and percentage of children receiving RRT with each of the major reported comorbidities over the last 15 years. As before, any apparent differences may be as a result of small numbers

Table 4.9. Number and percentage of children $<16$ years old who commenced RRT by age group and 5 -year period at start of RRT

\begin{tabular}{|c|c|c|c|c|c|c|}
\hline \multirow[b]{2}{*}{ Age group (years) } & \multicolumn{2}{|c|}{ 2000-2004 } & \multicolumn{2}{|c|}{ 2005-2009 } & \multicolumn{2}{|c|}{ 2010-2014 } \\
\hline & $N$ & $\%$ & $N$ & $\%$ & $N$ & $\%$ \\
\hline $0-<2$ & 72 & 13.6 & 109 & 17.9 & 96 & 17.2 \\
\hline $2-<4$ & 44 & 8.3 & 48 & 7.9 & 71 & 12.7 \\
\hline $4-<8$ & 80 & 15.1 & 101 & 16.6 & 92 & 16.5 \\
\hline $8-<12$ & 136 & 25.7 & 127 & 20.9 & 125 & 22.4 \\
\hline $12-<16$ & 198 & 37.4 & 224 & 36.8 & 174 & 31.2 \\
\hline 16 & 530 & & 609 & & 558 & \\
\hline
\end{tabular}


Table 4.10. Number* and percentage of children under 16 years who commenced RRT, by ethnicity and 5-year period of starting RRT

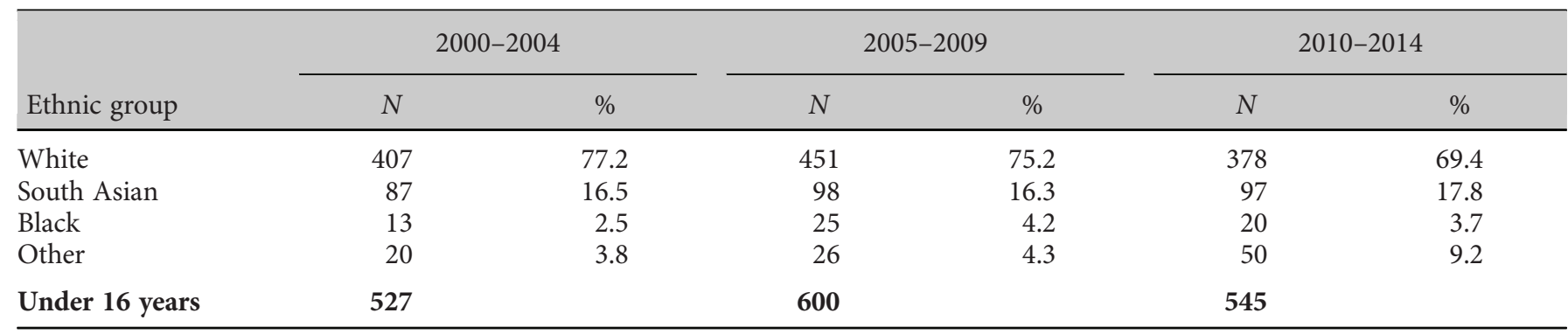

${ }^{*}$ Three children in 2000-2004, nine in 2005-2009 and 13 in 2010-2014 with no ethnicity recorded are excluded from this table

Table 4.11. Number and percentage of children under 16 years by renal centre and 5 -year period of starting RRT

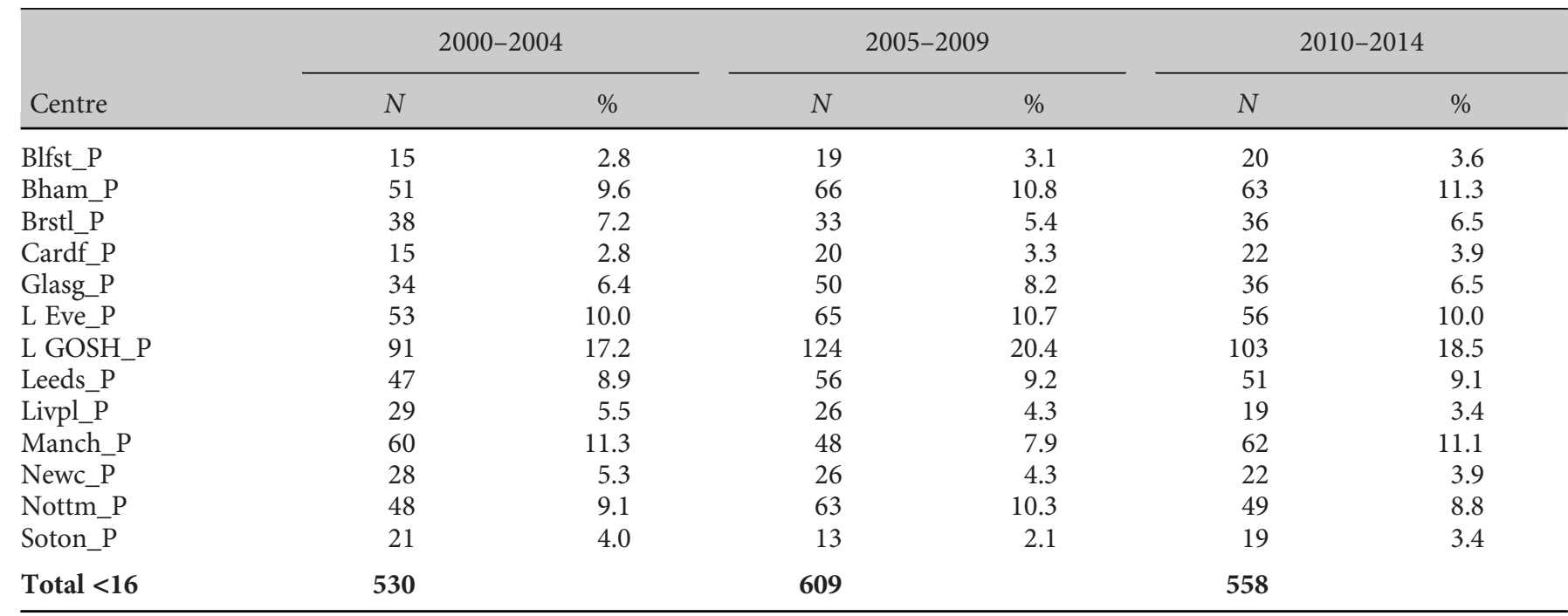

Table 4.12. Trends in reported comorbidity frequency at the start of RRT in the paediatric population under 16 years by 5 -year period

\begin{tabular}{|c|c|c|c|c|c|c|}
\hline \multirow[b]{2}{*}{ Comorbidity } & \multicolumn{2}{|c|}{ 2000-2004 } & \multicolumn{2}{|c|}{ 2005-2009 } & \multicolumn{2}{|c|}{ 2010-2014 } \\
\hline & $N$ & $\%$ & $N$ & $\%$ & $N$ & $\%$ \\
\hline Syndromic diagnosis & 41 & 7.7 & 53 & 8.7 & 39 & 7.0 \\
\hline Developmental delay & 44 & 8.3 & 44 & 7.2 & 36 & 6.5 \\
\hline Congenital abnormality & 44 & 8.3 & 57 & 9.4 & 30 & 5.4 \\
\hline Prematurity & 27 & 5.1 & 31 & 5.1 & 28 & 5.0 \\
\hline Consanguinity & 25 & 4.7 & 18 & 3.0 & 23 & 4.1 \\
\hline Family member with ERF & 19 & 3.6 & 15 & 2.5 & 11 & 2.0 \\
\hline Liver disease & 7 & 1.3 & 12 & 2.0 & 8 & 1.4 \\
\hline Neural tube defect & 0 & & 6 & 1.0 & 6 & 1.1 \\
\hline Psychological disorder & 11 & 2.1 & 7 & 1.1 & 6 & 1.1 \\
\hline Cerebral palsy & 10 & 1.9 & 11 & 1.8 & 5 & 0.9 \\
\hline Congenital heart disease & 10 & 1.9 & 23 & 3.8 & 4 & 0.7 \\
\hline Malignancy & 8 & 1.5 & 4 & 0.7 & 3 & 0.5 \\
\hline Chromosomal abnormality & 17 & 3.2 & 19 & 3.1 & 2 & 0.4 \\
\hline Diabetes & 6 & 1.1 & 3 & 0.5 & 0 & \\
\hline No reported comorbidity & 338 & 63.8 & 415 & 68.1 & 417 & 74.7 \\
\hline One reported comorbidity & 137 & 25.8 & 123 & 20.2 & 96 & 17.2 \\
\hline Two or more comorbidities & 55 & 10.4 & 71 & 11.7 & 45 & 8.1 \\
\hline
\end{tabular}

ERF - established renal failure 


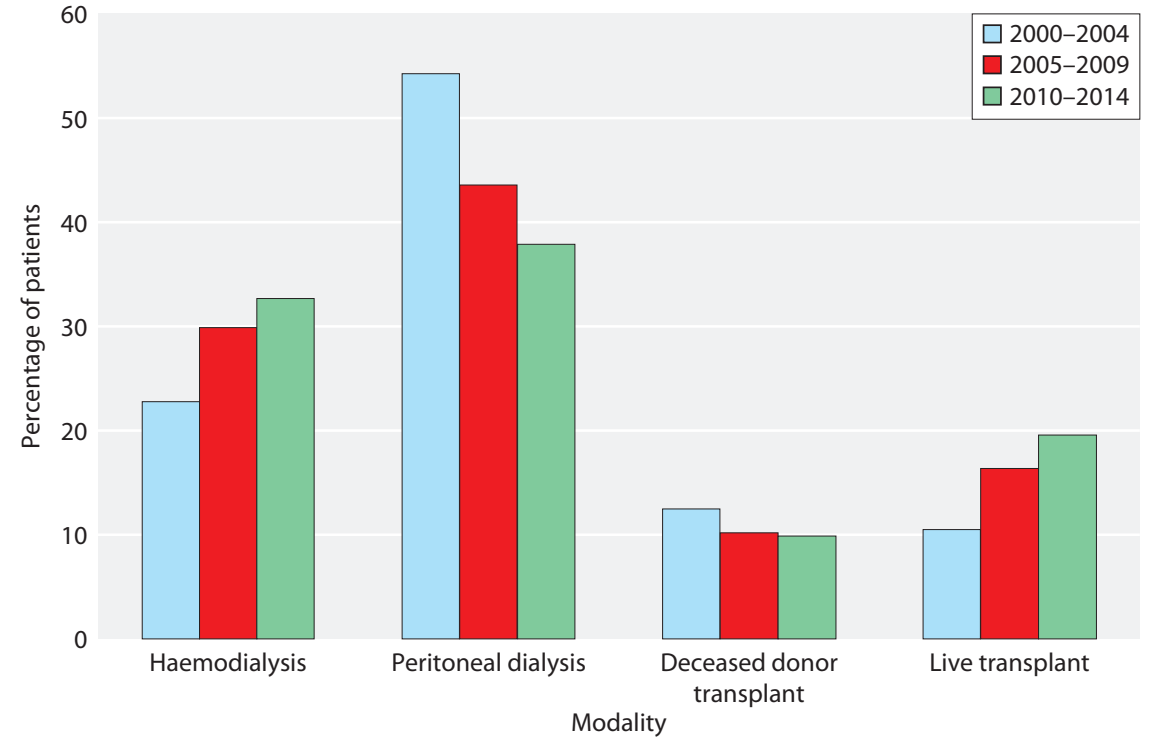

Fig. 4.4. Treatment modality at start of RRT by 5 -year time period between groups. Overall there is a trend towards the reporting of less comorbidity in children receiving RRT over the last 15 years and as previously mentioned, it is not clear whether this is due to reporting or differences in case selection.

The continued fall in the use of deceased donor transplants at the start of RRT demonstrated in previous reports [1] appears to have stabilised as seen in figure 4.4, with little change between the most recent five year periods. Use of $\mathrm{PD}$ as a start modality has fallen from $54 \%$ in $2000-2004$ to $38 \%$ in $2010-2014$, being replaced with increasing use of $\mathrm{HD}$ and living kidney donation.

Glomerular disease as a cause of ERF has fallen compared to other PRDs in the prevalent paediatric population over the last fifteen years, as shown in table 4.13.

\section{Pre-emptive transplantation}

Of a total of 1,697 patients aged $0-16$ years who started RRT between 2000 and 2014, 465 patients were excluded from this analysis (95 patients due to being aged $<3$ months, 369 due to being late presenters, and one additional patient with unclear dates). Of 1,232 patients identified as being aged three months to $<16$ years and having started RRT between 2000-2014, table 4.14 shows that a third of patients had a pre-emptive transplant.

There was a significant difference in pre-emptive transplantation rates by time period (higher rates more recently, $p=0.005$ ), with similar rates between the two most recent five year periods.

There remained a significant difference in pre-emptive transplantation rates with higher rates in boys $(p=0.01)$,

Table 4.13. Number ${ }^{*}$ and percentage of primary renal diseases in prevalent paediatric patients under 16 years by 5 -year time period

\begin{tabular}{|c|c|c|c|c|c|c|}
\hline \multirow[b]{2}{*}{ Primary renal diagnosis } & \multicolumn{2}{|c|}{ 2000-2004 } & \multicolumn{2}{|c|}{ 2005-2009 } & \multicolumn{2}{|c|}{ 2010-2014 } \\
\hline & $N$ & $\%$ & $N$ & $\%$ & $N$ & $\%$ \\
\hline Renal dysplasia \pm reflux & 159 & 30.4 & 194 & 32.4 & 182 & 33.6 \\
\hline Obstructive uropathy & 77 & 14.7 & 83 & 13.9 & 98 & 18.1 \\
\hline Glomerular disease & 119 & 22.8 & 122 & 20.4 & 68 & 12.6 \\
\hline Congenital nephrotic syndrome & 24 & 4.6 & 36 & 6.0 & 36 & 6.7 \\
\hline Tubulo-interstitial disease & 43 & 8.2 & 49 & 8.2 & 43 & 7.9 \\
\hline Uncertain aetiology & 14 & 2.7 & 35 & 5.8 & 39 & 7.2 \\
\hline Renovascular disease & 25 & 4.8 & 20 & 3.3 & 16 & 3.0 \\
\hline Polycystic kidney disease & 14 & 2.7 & 18 & 3.0 & 24 & 4.4 \\
\hline Metabolic & 28 & 5.4 & 29 & 4.8 & 30 & 5.5 \\
\hline Malignancy \& associated disease & 10 & 1.9 & 9 & 1.5 & 5 & 0.9 \\
\hline Drug nephrotoxicity & 10 & 1.9 & 4 & 0.7 & 0 & 0.0 \\
\hline
\end{tabular}

${ }^{*}$ Seven children in 2000-2004, 10 in 2005-2009 and 17 in 2010-2014 with no primary renal diagnosis recorded are excluded from this table 
Table 4.14. Demographic characteristics of pre-emptive transplantation in children aged three months to 16 years in the UK between 2000-2014, analysed by 5-year time period, gender, ethnicity, age at start of RRT and primary renal diagnosis

\begin{tabular}{|c|c|c|}
\hline & $N$ & $\begin{array}{c}N(\%) \\
\text { pre-emptively } \\
\text { transplanted }\end{array}$ \\
\hline Total cohort analysed (2000-2014) & 1,232 & $417(33.8)$ \\
\hline $\begin{array}{l}\text { Time period } \\
2000-2004 \\
2005-2009 \\
2010-2014\end{array}$ & $\begin{array}{l}390 \\
426 \\
416\end{array}$ & $\begin{array}{l}107(27.4) \\
154(36.2) \\
156(37.5)\end{array}$ \\
\hline $\begin{array}{l}\text { Gender } \\
\text { Male } \\
\text { Female }\end{array}$ & $\begin{array}{l}773 \\
459\end{array}$ & $\begin{array}{l}282(36.5) \\
135(29.4)\end{array}$ \\
\hline $\begin{array}{l}\text { Ethnicity } \\
\text { White } \\
\text { South Asian } \\
\text { Black } \\
\text { Other }\end{array}$ & $\begin{array}{r}899 \\
209 \\
39 \\
62\end{array}$ & $\begin{array}{r}330(36.7) \\
47(22.5) \\
6(15.4) \\
23(37.1)\end{array}$ \\
\hline $\begin{array}{l}\text { Age at start of RRT (years) } \\
3 \text { months }-<2 \\
2-<4 \\
4-<8 \\
8-<12 \\
12-<16\end{array}$ & $\begin{array}{l}123 \\
137 \\
220 \\
304 \\
448\end{array}$ & $\begin{aligned} & (5.7) \\
38 & (27.7) \\
88 & (40) \\
110 & (36.2) \\
174 & (38.8)\end{aligned}$ \\
\hline $\begin{array}{l}\text { Primary renal diagnosis } \\
\text { Renal dysplasia } \pm \text { reflux } \\
\text { Obstructive uropathy } \\
\text { Glomerular disease } \\
\text { Congenital nephrotic syndrome } \\
\text { Tubulo-interstitial disease } \\
\text { Metabolic } \\
\text { Polycystic kidney disease } \\
\text { Uncertain aetiology } \\
\text { Renovascular disease } \\
\text { Malignancy \& associated disease } \\
\text { Drug nephrotoxicity }\end{array}$ & $\begin{array}{r}410 \\
217 \\
205 \\
81 \\
76 \\
74 \\
46 \\
39 \\
37 \\
15 \\
6\end{array}$ & $\begin{aligned} 173 & (42.2) \\
101 & (46.5) \\
25 & (12.2) \\
4 & (4.9) \\
17 & (22.4) \\
31 & (41.9) \\
23 & (50) \\
11 & (28.2) \\
15 & (40.5) \\
1 & (6.7) \\
1 & (16.7)\end{aligned}$ \\
\hline
\end{tabular}

although this difference was not significant when adjusted for other factors in a logistic regression. Pre-emptive transplantation rates were higher in White versus non-White ethnicity $(p<0.0001)$. Rates also differed with PRD (lower in glomerular diseases versus renal dysplasia \pm reflux nephropathy and obstructive uropathies, $p<$ $0.0001)$. Children with polycystic kidney disease, obstructive uropathy, renal dysplasia \pm reflux, metabolic causes and renovascular diseases had the highest rates of preemptive transplantation, whilst those with congenital nephrotic syndrome had the lowest rate.

Analysis by age at start of RRT showed that as expected, the lowest rate of pre-emptive transplantation was in the three months to two year group, whilst children aged four to sixteen years all had similar rates of pre-emptive transplantation. Following exclusion of the youngest age group, there was no difference in preemptive transplantation rates by age.

Transfer of patients to adult renal services in 2014

Ninety three patients were reported by paediatric nephrology centres to have transferred to adult renal services in 2014, fairly consistent with the 101 who transferred during 2013 [1]. The median age of patients transferred out was 18.1 years with an inter-quartile range of 17.8 to 18.5 years. Table 4.15 shows that the demographics of those transferring out were very similar to that of the overall prevalent paediatric RRT population, but with over $90 \%$ having a functioning transplant.

\section{Survival of children on RRT during childhood}

Of patients under 16 years of age, 1,583 were identified as starting RRT between 2000 and 2013 at paediatric centres in the UK and were included in the survival

Table 4.15. Modality, gender, ethnicity and primary renal diagnosis of patients transferred out from paediatric nephrology centres to adult renal services in 2014

\begin{tabular}{|c|c|c|}
\hline & $N$ & $\%$ \\
\hline \multicolumn{3}{|l|}{ Modality } \\
\hline Transplant & 84 & 90.3 \\
\hline $\mathrm{HD}$ & 6 & 6.5 \\
\hline $\mathrm{PD}$ & 3 & 3.2 \\
\hline \multicolumn{3}{|l|}{ Gender } \\
\hline Male & 53 & 57.0 \\
\hline Female & 40 & 43.0 \\
\hline \multicolumn{3}{|l|}{ Ethnicity } \\
\hline White & 63 & 67.7 \\
\hline South Asian & 15 & 16.1 \\
\hline Other & 9 & 9.7 \\
\hline Black & 6 & 6.5 \\
\hline \multicolumn{3}{|l|}{ Primary renal diagnosis } \\
\hline Renal dysplasia \pm reflux & 28 & 30.1 \\
\hline Glomerular disease & 27 & 29.0 \\
\hline Obstructive uropathy & 13 & 14.0 \\
\hline Tubulo-interstitial disease & 10 & 10.8 \\
\hline Congenital nephrotic syndrome & 4 & 4.3 \\
\hline Polycystic kidney disease & 4 & 4.3 \\
\hline Metabolic & 3 & 3.2 \\
\hline Uncertain aetiology & 2 & 2.2 \\
\hline Malignancy \& associated disease & 1 & 1.1 \\
\hline Renovascular disease & 1 & 1.1 \\
\hline Drug nephrotoxicity & 0 & \\
\hline
\end{tabular}

HD - haemodialysis; PD - peritoneal dialysis 
Table 4.16. Survival hazard ratio during childhood for paediatric RRT patients aged $<16$ years in the UK adjusted for age at start of RRT, gender and RRT modality

\begin{tabular}{lccc}
\hline & $\begin{array}{c}\text { Hazard } \\
\text { ratio }\end{array}$ & $\begin{array}{c}\text { Confidence } \\
\text { interval }\end{array}$ & $p$-value \\
\hline Age (years) & & & \\
$0-<2$ & 4.1 & $2.2-8.0$ & $<0.0001$ \\
$2-<4$ & 2.1 & $1.0-4.3$ & 0.06 \\
$4-<8$ & 2.0 & $0.9-4.1$ & 0.08 \\
$8-<12$ & 1.4 & $0.6-3.1$ & 0.5 \\
$12-<16$ & 1.0 & - & \\
Gender & & & \\
Female & 1.2 & $0.7-1.8$ & 0.5 \\
Male & 1.0 & - & \\
RRT modality & & & \\
Dialysis & 6.3 & $3.9-10.2$ & $<0.0001$ \\
Transplant & 1.0 & - & \\
\hline
\end{tabular}

analyses. At the census date (31st December 2014) there were a total of 99 deaths reported in children on RRT under 16 years of age at paediatric centres. The median follow up time was 3.5 years (range of 1 day to 14.5 years). Table 4.16 shows the survival hazard ratios (following adjustment for age at start of RRT, gender and RRT modality) and highlights that children starting RRT under two years of age had the worst survival outcomes with a hazard ratio of 4.1 (confidence interval (CI) $2.2-8.0, p<0.0001$ ) when compared to $12-16$ year olds. Being on dialysis was seen to lower survival significantly compared to having a functioning transplant with a hazard ratio of 6.3 (CI 3.9-10.3, $p<0.0001$ ). There was insufficient power to add PRD to the model; drug induced nephrotoxicity and metabolic PRDs had the worst survival but confidence intervals were wide and included no effect. Figure 4.5 shows unadjusted Kaplan Meier (KM) survival probabilities and highlights worse outcomes for those aged less than two years, particularly during the first year.

\section{Mortality data in 2014}

Six deaths occurred in paediatric renal centres in 2014; four were in patients aged under two years and two were in 15 year olds. The median age at death was 1.5 years with a range of 0.4 years to 15.9 years. In children aged $<16$ years with treated ERF, the total reported mortality in 2014 in UK paediatric centres was $0.8 \%$ (6/734), and $2.9 \%(5 / 175)$ for those on dialysis.

\section{Transplant deaths}

At the time of death, one adolescent had received a kidney transplant. The cause of death was intractable seizures in the context of a previously undiagnosed mitochondrial disorder.

\section{Dialysis deaths}

At the time of death, three children were on dialysis (two HD and one PD). One HD patient died as a result of substance abuse on a background of poor compliance, and the second had a sudden unexplained death. Infection was the cause of death in the PD patient. Two further children died whilst receiving active palliative care, both having withdrawn from PD.

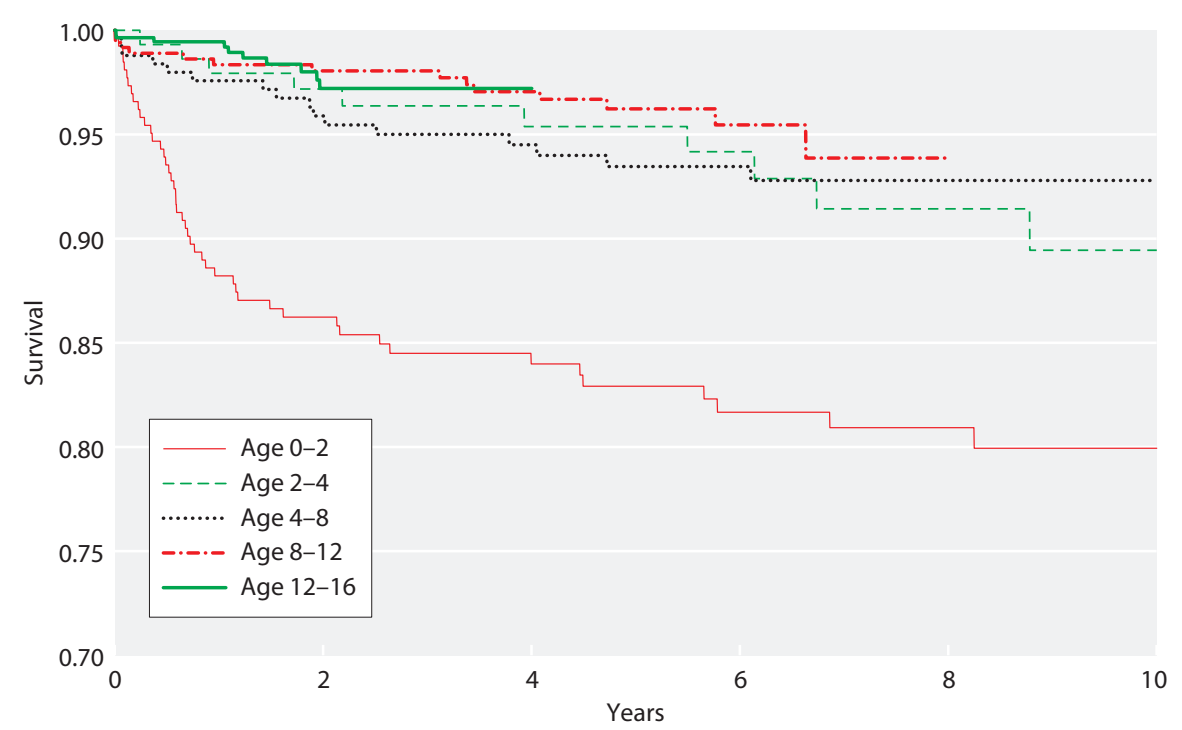

Fig. 4.5. Unadjusted KM survival in paediatric patients $<16$ years old starting RRT between 2000 and 2013, by age at start 


\section{Discussion}

This report provides the paediatric nephrology community with a unique resource of data on the demographics of the UK paediatric RRT population from the previous year, as well as allowing comparison of trends over the last fifteen years. This information is vital for commissioning of such a tertiary service, and data is also contributed to European registry reports to allow for international comparisons.

\section{Data returns}

Paediatric nephrology in the UK faces the challenge of being mandated to submit electronic data on small numbers of patients to the UKRR, sometimes in the context of being 'shoehorned' into using renal computer systems designed to collect registry data for adult patients. This often results in the need for additional data collection for the paediatric-specific dataset. Unsurprisingly, submission of data to the UKRR remained variable. Improved infrastructure, funding and familiarity with extraction procedures are required, and when staff or computer systems change fresh investment by centres is needed to successfully manage the process. Issues are faced when centres lack financial resources for a renal computer system that supports UKRR specific data collection, or there is not widespread use of such systems by clinical staff. This year, the majority of 2014 data returns breached the target submission date which affects the UKRR's ability to produce the Annual Report on time. In spite of this all centres are included. Despite a standardised dataset, the extracts received by the UKRR usually required extensive manipulation to allow them to be uploaded into the database. Once submitted data has been checked and validated they are returned to submitting renal centres with the onus on clinicians to provide any missing data items. A system is being devised to mark unobtainable missing data and to 'write off' such, to minimise requests to clinicians. Feedback on improving the process is always welcomed.

\section{Highlights from the 2014 data}

Incident and prevalent rates showed no major changes over time. Overall the prevalent population remained largely White, male and predominantly aged $>8$ years, with a functioning transplant.

Again the data shows most paediatric patients starting RRT do so on PD, with stable pre-emptive transplant rates. Current treatment modality is subject to variation over time in the youngest children as they are few.
Previous reports have shown decreasing use of preemptive deceased donor transplants over time [1]. In the 2014 data, this showed a plateau in the most recent five year periods at $10 \%$. Pre-emptive transplantation was observed to be influenced by ethnicity and PRD.

Structural renal disorders remained the main cause of ERF. The proportion of glomerular disease in the paediatric RRT population has fallen by $10 \%$ since 2000-2004. It would be interesting to know if this is due to better treatment preserving renal function for longer and therefore a corresponding increase in those with earlier stages of chronic kidney disease due to glomerular pathologies.

On the whole it would appear that most paediatric patients start RRT without comorbidity but reporting varied by centre. It will be useful to compare the data before and after our data quality exercise which is further discussed below.

A higher proportion of transplanted patients (90\%) transferred to adult services in 2014 than the previous year (85\%) which is reassuring, but these figures are prone to fluctuation due to small absolute numbers. A project to examine the long term survival of paediatric renal transplants in adulthood in the UK is planned to further explore this.

Survival analysis continues to show the negative influence of young age and dialysis modality. As in previous years, there were few deaths in 2014; however the death of a teenager from substance abuse highlights the likely benefit of additional psychosocial aspects to the reported paediatric data. The forthcoming Surveying Patients Experiencing young Adult Kidney failure (SPEAK) study will be collecting such data on 16-30 year olds receiving RRT in the UK. Information about the study can be found at https://www. renalreg.org/projects/speak/.

\section{Current and future work}

In 2016, the BAPN Audit \& Registry Committee will be hosting an event for all those involved in paediatric UKRR data, including administrative staff, managers, information technology staff and clinicians. The aim will be to share best practice and identify improvement areas. The UKRR is also reviewing the support that can be given to centres and may be able to offer a paid extraction service for paediatric centres in the future. In 2014, only one centre was unable to provide an extract, instead using a data collection form, and it is hoped such an event can achieve the aim of extracts in all centres.

Centres will be contacted with the aim of completing comorbidity and disability data for prevalent patients 
where this may have been submitted unclearly making it impossible to differentiate between a condition being not present in the patient or this information not being available at the time of submission. Once complete it will be possible to comment with more confidence if there are inter-centre differences in the rates of offering RRT to patients with additional comorbidities.

The grouping system for PRD codes is also being reviewed and is unique to the UKRR. These are grouped differently to the adult Report, with many paediatric conditions being lost into the broad 'other' adult category, should that be used. A change now would make past comparisons more difficult but moving forwards to the use of the most recent 2012 ERA-EDTA PRD groupings needs to be considered. This framework uses five groups which would lose some of the detail presented in this report.

A UKRR project presenting data for young adults from both adult and paediatric databases has been completed and should achieve publication in the near future.

A significant step towards merging new data in the adult and paediatric databases has been made this year, in that quarterly laboratory data has been submitted by ten centres. This data is reported in chapter 10. Uniform extracts and quarterly reporting will enable the loading of new data into the adult dataset (although the historic paediatric data will be held separately), allowing analysis of all 16-18 year olds rather than just those reported by paediatric centres.

\section{Acknowledgement}

Thanks are expressed to Kidney Research UK and the British Kidney Patient Association whose contribution through the Tony Wing award contributed to the production of this chapter.

Conflicts of interest: the authors declare no conflicts of interest

\section{References}

1 Pruthi R, Hamilton AJ, O'Brien C, Casula A, Braddon F, Inward C, Lewis M, Maxwell H, Stojanovic J, Tse Y, Sinha MD. UK Renal Registry 17th Annual Report: Chapter 4 Demography of the UK Paediatric Renal Replacement Therapy Population in 2013. Nephron. 2015;129 (suppl 1):87-98. doi: 10.1159/000370274

2 NHS England. 2013/14 NHS Standard Contract for Paediatric Medicine: Renal. Particulars, Schedule 2 - The Services, A - Service Specification http://www.england.nhs.uk/wp-content/uploads/2013/06/e03-paedi-medirenal.pdf

3 http://www.Ons.Gov.Uk/census

4 Pruthi R, O’Brien C, Casula A, Braddon F, Lewis M, Maxwell H, Tse Y, Inward C, Sinha MD. UK Renal Registry 15th Annual Report (December 2011): Chapter 4 Demography of the UK Paediatric Renal Replacement Therapy Population in 2011. Nephron Clin Pract. 2013; 123(suppl 1): 81-92. doi: $10.1159 / 000353323$ 